\title{
SGIP1a functions as a selective endocytic adaptor for the internalization of synaptotagmin 1 at synapses
}

\author{
Sang-Eun Lee, Soomin Jeong, Unghwi Lee and Sunghoe Chang ${ }^{*}$
}

\begin{abstract}
Proper sorting of exocytosed synaptic vesicle (SV) proteins into individual SVs during endocytosis is of the utmost importance for the fidelity of subsequent neurotransmission. Recent studies suggest that each SV protein is sorted into individual SVs by its own dedicated adaptors as well as by association between SV proteins. The SH3containing GRB2-like protein 3-interacting protein 1 (SGIP1), an ortholog of Fer/Cip4 homology domain-only (FCHo) proteins, contains a $\mu$-homology domain $(\mu \mathrm{HD})$ and binds AP-2 and Eps15, thus functioning as an endocytic regulator of clathrin-mediated endocytosis (CME). Its longest isoform SGIP1a is predominantly expressed in the brain but the functional significance of SGIP1 in SV recycling remains unknown. Here, we found that SGIP1a, a brain-specific long isoform of SGIP1 binds synaptotagmin1 (Syt1) via its $\mu \mathrm{HD}$ and promotes the internalization of Syt1 on the neuronal surface. The small hairpin RNA (shRNA)-mediated knockdown (KD) of SGIP1a caused selective impairment of Syt1 internalization at hippocampal synapses and it was fully rescued by coexpression of the shRNAresistant form of SGIP1a in KD neurons. We further found that the $\mu \mathrm{HD}$ of SGIP1a is structurally similar to those of AP-2 and stonin2, and mutations at Trp771 and Lys781, which correspond to Syt1-recognition motifs of AP-2 and stonin2, to Ala bound less efficiently to Syt1 and failed to rescue the endocytic defect of Syt1 caused by KD. Our results indicate that SGIP1a is an endocytic adaptor dedicated to the retrieval of surface-stranded Syt1. Since endocytic sorting of Syt1 is also mediated by the overlapping activities of synaptic vesicle glycoprotein 2A/B (SV2A) B) and stonin2, our results suggest that complementary fail-safe mechanism by these proteins ensures high fidelity of Syt1 retrieval.
\end{abstract}

Keywords: SGIP1a, synaptotagmin 1, Synaptic vesicle, Clathrin-mediated endocytosis

\section{Introduction}

Neurotransmission involves the calcium $\left(\mathrm{Ca}^{2+}\right)$-regulated fusion of SVs, a process that requires the $\mathrm{Ca}^{2+}$ sensor Syt1 at the active zone, which defines sites of neurotransmitter release [1]. Post-exocytic SV proteins are retrieved by endocytosis from the plasma membrane to regenerate new SVs [2]. More than forty different integral membrane proteins that are essential for SV trafficking and neurotransmission were identified and they should be incorporated into individual SVs with the correct stoichiometry to be functional for subsequent

\footnotetext{
* Correspondence: sunghoe@snu.ac.kr

Department of Physiology and Biomedical Sciences, Neuroscience Research Institute, Seoul National University College of Medicine, Seoul 03080, South Korea
}

exocytosis [3, 4]. Indeed, some SV proteins including Syt1, vesicular glutamate transporter 1(vGlut1), and SV2A/B display little inter-vesicle variation, thus elaborate molecular mechanisms must exist to control the fidelity of SV protein sorting while maintaining the speed of exo-endocytosis [5]. One possibility is that exocytosed SV proteins remain clustered at the active zone and are then retrieved as a cluster during endocytosis as in the case of a specific exocytic mode called kiss-and-run [6]. Alternatively, each SV protein is precisely recruited to individual SVs by cargo-specific recognition and sorting by dedicated adaptors [7]. Indeed, recent studies have identified various cargo-specific adaptors including AP180/CALM as adaptors for vesicle associated membrane protein 2 (VAMP2; also referred to as synaptobrevin2) [8-10], and SV2A/B/stonin2 as adaptors for Syt1 
[5, 11-14]. Such that each regenerated individual synaptic vesicle will obtain all essential synaptic vesicle proteins with high fidelity. In addition, recent studies indicated that the association between SV proteins is also critical for their accurate retrieval and sorting into SVs. For example, synaptophysin and SV2A/B associates with VAMP2 and Syt1, respectively, facilitating their endocytic retrieval $[15,16]$.

Syt1, a $65 \mathrm{kDa} \mathrm{SV}$ protein, is the major $\mathrm{Ca}^{2+}$ sensor for $\mathrm{SV}$ exocytosis. It contains two $\mathrm{C} 2$ domains (termed $\mathrm{C} 2 \mathrm{~A}$ and $\mathrm{C} 2 \mathrm{~B}$ ) and is anchored to the membrane by a single $\mathrm{N}$-terminal transmembrane domain $[17,18]$. Previous studies proved that a fast synchronous component of glutamate release was mostly abolished in hippocampal neurons of Syt1 knock-out (KO) mice [17, 18]. Evidently, it is an indispensable SV cargo and previous studies showed that endocytic sorting of Syt1 is mediated by the overlapping activities of stonin 2 and SV2A/B, thus suggesting that both cargo-specific, as well as the association between SV proteins, ensure proper sorting of essential Syt1 into SVs [19, 20]. Interestingly, the similar endocytic defects of Syt1 in neurons lacking either SV2A/B or stonin2 has been found, indicating that these molecules are functionally redundant for Syt1 retrieval $[13,15,19,20]$. Considering the role of Syt1 as an exocytic regulator, such fail-safe mechanism is essential for accurate Syt1 retrieval.

The SGIP1 was first discovered by the differential display PCR analysis of hypothalamus RNA from lean and obese P. obesus (Psammomys obesus; Israeli sand rat) [21]. Targeted reduction of hypothalamic SGIP1 mRNA by infusion of antisense oligonucleotides inhibited food intake and decreased body weight in P. obesus [21]. Since SGIP1 interacts with endophilin, a mediator of vesicle recycling and endocytosis, it is known as an endocytic protein that has a functional role in neuronal systems in energy homeostasis [21-23]. Recent studies further identified SGIP1 as a homolog of FCHo1/2, a muniscin family member of key endocytic adaptors of CME [24-27]. The muniscin family has conserved $\mathrm{N}$-terminal domain homologous to the crescent-shaped membrane-tubulating EFC/F-BAR domains and a C-terminal $\mu \mathrm{HDs}$ that interact with the endocytic adaptor/scaffold Ede1/Eps15 [28]. SGIP1 has the membrane phospholipid-binding residue in $\mathrm{N}$-terminal instead of EFC-BAR domains and a C-terminal $\mu \mathrm{HD}$ [23]. SGIP1 $\alpha$ is the brain-specific and the longest splicing variant of SGIP1 [23]. Compared to SGIP1, SGIP1 $\alpha$ has two additional regions: an additional 28 amino acids (aa 34-61) in N-terminal, and another extra 20 amino acids (aa 550-569) in a C-terminal [23]. SGIP1 $\alpha$ interacts with Eps15 [29], intersectin [30], and AP-2 [25] and is suggested to play a role in CME [23]. Despite its possibility, however, the functional significance of SGIP1 $\alpha$ in the brain, especially during $\mathrm{SV}$ recycling, remains unknown.
In this study, we identified SGIP1 $\alpha$ as a novel interactor of Syt1 at hippocampal neurons. We found that the C2 domains of Syt1 interact with $\mu \mathrm{HD}$ of SGIP1 $\alpha$ and SGIP1 $\alpha$ functions as a selective sorting adaptor for endocytic internalization and sorting of Syt1. We further found that $\mu \mathrm{HD}$ of SGIP1 $\alpha$ is structurally similar to those of AP-2 and stonin2, which are known endocytic adaptors for Syt1. Together, we proposed the complementary fail-safe mechanism for Syt1 retrieval by SV2A/B-stonin2-SGIP1 $\alpha$ which allows synapses to ensure the accurate sorting of Syt1 for subsequent neurotransmission.

\section{Materials and methods \\ DNA constructs}

Full-length mouse GFP- tagged SGIP1 plasmid was kindly provided by Marek Michalak (University of Alberta, Edmonton, Alberta, Canada). Recombinant human GST-Syt1-C2AB domain was kindly provided by Dr. Namgi Lee (Seoul National University, Seoul, Korea). Synaptophysin-pHluorin, VAMP2-pHluorin, and Syt1-pHluorin were provided by Dr. Leon Lagnado (Medical Research Council), Dr. J. Rothman (Sloan Kettering Cancer Center) and Dr. Volker Haucke (Leibniz Institute for Molecular Pharmacology), respectively. We generated full-length SGIP1 $\alpha$ (NM_001285852.1) by inserting additional amino acid sequence in GFP-SGIP1 template by PCR and then ligated into the XhoI-KpnI sites in HA-C1 vector and FLAG-C1 vector. By application of PCR site-directed mutagenesis, we prepared several SGIP1 mutation constructs: HA-SGIP1 $\alpha-\mu \mathrm{HD}$ (aa 550-854), HA-SGI$P 1 \alpha-\Delta \mu H D$ (aa 1-549) and HA-SGIP1 $\alpha$-mut (W771A/ K781A). The fidelity of all constructs was verified by DNA sequencing. DNA constructs were purified from E.coli DH5 $\alpha$ using a midi prep kit (Promega, Madison, WI) according to the instructions of the manufacturer.

\section{RNA-mediated interference and rescue experiments}

The RNA interference (RNAi)-mediated SGIP1 KD was carried out by expressing shRNA through pU6 expression vector. Designed shRNA was cloned into the pSIREN-U6mRFP vector (Clontech, Palo Alto, CA) for transient transfection or AAV-U6-GFP vector (Cell Biolabs, San Diego, $\mathrm{CA})$ for adeno-associated virus (AAV) production. The targeted sequence of mouse SGIP1 from its cDNA sequence was 5'- GGTTCTTTACTGGCGAGATTT -3' (nucleotides 2386-2406) common to rat SGIP1 cDNA sequence. In particular, this target sequence is also present in all five isoforms of SGIP1. The down-regulation efficiency of shRNA was examined in AAV -infected cortical neurons. To exclude the artificial effects of the expression vector, a scrambled sequence of the forward primer was designed; $5^{\prime}-$ GTGG CCTGTAGTTTAGTTACT - 3' (http://www.sirnawizard. $\mathrm{com} /$ ). The BFP-shRNA-resistant form was manipulated from GFP-tagged SGIP1 $\alpha$ by point mutation. All constructs 
were verified by sequencing. After transfection, cells were cultured for more than $72 \mathrm{~h}$.

\section{Antibodies \\ Mouse polyclonal anti- $\beta$-tubulin was purchased from Abcam (Cambridge, UK). Mouse monoclonal HA antibody was pur- chased from COVANCE (Princeton, SN). Anti-Syt1 was from Synaptic Systems (Göttingen, Germany). Anti-SGIP1 was purchased from Sigma-Aldrich (Merck, Darmstadt, Germany), HRP-conjugated anti-rabbit or anti-mouse sec- ondary antibodies were from Jackson ImmunoResearch (West Grove, PA).}

\section{Cell culture and transfection}

Human embryonic kidney (HEK) $293 \mathrm{~T}$ cells (ATCC, Manassas, VA) were cultured at $37^{\circ} \mathrm{C}$, in air supplemented with $5 \% \mathrm{CO}_{2}$ and in Dulbecco's modified Eagle's medium (Invitrogen, Carlsbad, CA) supplemented with $10 \%$ fetal bovine serum (GE Healthcare Life Sciences, Uppsala, Sweden). Transfection was carried out using Lipofectamine 2000 (Invitrogen), and cells were observed $36-48 \mathrm{~h}$ after transfection.

\section{Western blot}

HEK293T cells transfected with plasmids encoding FLAG-SGIP1 $\alpha$ or AAV-virus infected cortical neurons were washed three times with ice-cold PBS. Immunoblotting was performed from cell lysates generated in RIPA buffer (20 $\mathrm{mM}$ Tris, pH 7.5, $100 \mathrm{mM} \mathrm{NaCl}, 50 \mathrm{mM} \mathrm{NaF}, 1 \%$ SDS, 1 $\mathrm{mM}$ orthovanadate) supplemented with protease inhibitor cocktail (Roche, Mannheim, Germany). Protein concentrations were measured using a bicinchoninic acid (BCA) protein assay reagent kit (ThermoFisher, Waltham, MA). Protein extracts were separated by SDS-PAGE and transferred to polyvinylidene difluoride (PVDF) membranes (Pall Life Science, Ann Arbor, MI). The membranes were blocked for $1 \mathrm{~h}$ with $5 \%$ nonfat dry milk in TBS/T $(10 \mathrm{mM}$ Tris-Cl, $\mathrm{pH}$ 7.6, $100 \mathrm{mM} \mathrm{NaCl}$ and $0.1 \%$ Tween 20 ) and incubated with anti-SGIP1 (1:1000) or $\beta$-tubulin (1:1000) primary antibodies for $2 \mathrm{~h}$ at room temperature(RT) or overnight at $4{ }^{\circ} \mathrm{C}$, and with corresponding HRP-conjugated secondary antibody for $1 \mathrm{~h}$. Chemiluminescence reactions were performed with AbSignal Western detection kit system (AbClon, Seoul, South Korea) and detected using an ImageQuant LAS-4000 (GE Healthcare Life Sciences); images were analyzed by the ImageJ software (NIH, Bethesda, $\mathrm{MD}$ ).

\section{GST pull-down assays}

Recombinant human Syt1-C2AB domain with an $\mathrm{N}$-terminal GST tag was overexpressed in E.Coli BL21. Bacterial cells were grown in $5 \mathrm{~mL}$ of Luria-Bertani (LB) broth at $37^{\circ} \mathrm{C}$ for $2 \mathrm{~h}$ and subsequently inoculated to $200 \mathrm{~mL}$ 2xYT medium broth supplemented with $100 \mathrm{mg} / \mathrm{ml} \mathrm{Ampi-}$ cillin. Cultures were grown at $37^{\circ} \mathrm{C}$ for $\sim 4 \mathrm{~h}$ with vigorous shaking and overexpression was subsequently induced by $0.25 \mathrm{mM}$ isopropyl $\beta$-D-1-thiogalactopyranoside (IPTG) at $20^{\circ} \mathrm{C}$ for $16 \mathrm{~h}$. Bacterial cells were harvested by centrifugation at $4500 \mathrm{~g}$ and $4{ }^{\circ} \mathrm{C}$ for $15 \mathrm{~min}$, and the pellet was resuspended with hypotonic buffer $(20 \mathrm{mM}$ Tris- $\mathrm{HCl} \mathrm{pH} 8.0$, $150 \mathrm{mM} \mathrm{NaCl}, 1 \mathrm{mM}$ EGTA, $1 \mathrm{mM} \mathrm{MgCl}_{2}$ ) supplemented with protease inhibitor cocktail. Cells were lysed by sonication on ice and the cell extract was cleared from intact cells and debris by centrifugation at $16,000 \mathrm{~g}$ and $4{ }^{\circ} \mathrm{C}$ for $30 \mathrm{~min}$. After centrifugation, the supernatant was incubated with GST (GE Healthcare Life Sciences) beads for the in vitro binding assay. $24-48 \mathrm{~h}$ post-transfection, transiently transfected HEK293T cells were lysed in ice-cold buffer $(20 \mathrm{mM}$ Tris- $\mathrm{HCl} \mathrm{pH}$ 8.0, $137 \mathrm{mM} \mathrm{NaCl}, 2 \mathrm{mM}$ EDTA, $1 \%$ Triton X-100, 1 mM PMSF, 0.3\% inhibitor cocktail). Cleared cell extracts were incubated with GST fusion proteins on a rotator ( $1 \mathrm{mg}$ of cell extract at $1 \mathrm{mg} / \mathrm{ml}$ ) for $4 \mathrm{~h}$ at $4{ }^{\circ} \mathrm{C}$. After extensive washes, bound proteins were eluted with $30 \mu \mathrm{l}$ of SDS sample buffer. Samples were analyzed by Western blot.

\section{Primary neuron culture and transfection}

All of the animal experiments were performed according to the Institute of animal care and use committee (IACUC) guidelines of Seoul National University. Primary rat hippocampal or cortical neurons derived from embryonic day 18 Sprague Dawley fetal rats of either sex were prepared as described previously [31]. Briefly, hippocampi or prefrontal cortexes were dissected, dissociated with papain, and triturated with a polished half-bore pasteur pipette. Approximately $2.5 \times 10^{5}$ cells were resuspended in Hank's Balanced Salt Solution (HBSS, GE Healthcare Life Sciences) supplemented with $0.6 \%$ glucose, $1 \mathrm{mM}$ pyruvate, $2 \mathrm{mM} \mathrm{L}$-glutamine, and $10 \%$ (v/v) FBS (GE Healthcare Life Sciences) and plated on Poly-D-lysine-coated glass coverslips in a $60-\mathrm{mm}$ Petri dish. $4 \mathrm{~h}$ after plating, the medium was replaced with neurobasal medium (Invitrogen) supplemented with $2 \% \quad(\mathrm{v} / \mathrm{v}) \quad \mathrm{NS} 21, \quad 0.5 \mathrm{mM} \mathrm{L}$-glutamine. $4 \mathrm{mM}$ $1-\beta$-D-cytosine-arabinofuranoside (Ara-C; Sigma) was added as needed. Cortical neurons derived from prefrontal cortexes at a density of $5.0 \times 10^{6}$ were plated on poly-D-lysine-coated $100 \mathrm{~mm}$ Culture dish. Neurons were transfected using a modified $\mathrm{Ca}^{2+}$-phosphate method. Briefly, $6 \mu \mathrm{g}$ of DNA and $9.3 \mu \mathrm{l}$ of $2 \mathrm{M} \mathrm{CaCl}_{2}$ were mixed in distilled water to a total volume of $75 \mu \mathrm{l}$ and the same volume of 2xBBS (50 mM BES, $280 \mathrm{mM}$ $\mathrm{NaCl}$, and $1.5 \mathrm{mM} \mathrm{Na}_{2} \mathrm{HPO}_{4}, \mathrm{pH} 7.1$ ) was added. The cell culture medium was completely replaced by transfection medium (MEM; $1 \mathrm{mM}$ sodium pyruvate, $0.6 \%$ glucose, $10 \mathrm{mM}$ HEPES, $1 \mathrm{mM}$ Kynurenic acid, and 10 $\mathrm{mM} \mathrm{MgCl} 2, \mathrm{pH} 7.71$ ), and the DNA mixture was added to the cells and incubated in a $5 \% \mathrm{CO}_{2}$ incubator for 60 min. Cells were washed twice with a washing medium $(\mathrm{pH} 7.30)$, and then returned to the original culture 
medium. Neurons were co-transfected at days in vitro (DIV) 8-9 and analyzed at DIV 16-21. Co-transfection was performed at a ratio of 1:2 and triple-transfection at a ratio of $1: 1: 1$.

\section{Immunocytochemistry and image acquisition}

Cultured neurons were fixed in $4 \%(\mathrm{~V} / \mathrm{V})$ paraformaldehyde, $4 \%(\mathrm{~V} / \mathrm{V})$ sucrose in PBS for $15 \mathrm{~min}$ and subsequently permeabilized with $0.25 \%(\mathrm{~V} / \mathrm{V})$ Triton X-100 in PBS for $3 \mathrm{~min}$ at RT. Neurons were then blocked with $10 \%$ bovine serum albumin (BSA) in PBS for $1 \mathrm{~h}$ at RT. Primary antibodies diluted 1:500 in $3 \%(\mathrm{~V} / \mathrm{V})$ BSA in PBS were added and incubated for $2 \mathrm{~h}$ at RT. Secondary antibodies were diluted 1:2000 in 3\% (V/V) BSA in PBS and incubated for $1 \mathrm{~h}$ at RT. Immunofluorescence labeled cells were mounted and analyzed using Olympus IX-71 inverted microscope with 40X, 1.35 NA lens, an EMCCD camera (iXon897, Andor Technologies, Belfast, Northern Ireland) and MetaMorph Imaging software (Molecular Devices, San Jose, CA).

\section{pHluorin endocytosis assay and image analysis}

Coverslips were mounted in a perfusion/stimulation chamber equipped with platinum-iridium field stimulus electrodes (Chamlide; LCI, Korea) on the stage of an Olympus IX-71 inverted microscope. The cells were continuously perfused at $34{ }^{\circ} \mathrm{C}$ with tyrode solution containing the following: $136 \mathrm{mM} \mathrm{NaCl}, 2.5 \mathrm{mM} \mathrm{KCl}, 2 \mathrm{mM}$ $\mathrm{CaCl}_{2}, 1.3 \mathrm{mM} \mathrm{MgCl}_{2}, 10 \mathrm{mM}$ HEPES, and $10 \mathrm{mM}$ glucose, $\mathrm{pH}$ 7.3. The temperature of the chamber and lens was controlled by a heating controller system (LCI). $10 \mu \mathrm{M}$ 6-cyano-7-nitroquinoxaline-2,3-dione (CNQX) and $50 \mu \mathrm{M}$ of DL-2-amino-5-phosphonovaleric acid (AP-V) were added to imaging buffer to reduce spontaneous activity and to prevent recurrent excitation during stimulation. Time-lapse images were acquired every $5 \mathrm{~s}$ for $5 \mathrm{~min}$ using a back-illuminated Andor iXon 897 EMCCD camera driven by MetaMorph Imaging software. From the fifth frame, the cells were stimulated (1 ms, 20-50 V, bipolar) using an A310 Accupulser current stimulator (World Precision Instruments, Sarasota, FL). Quantitative measurements of the fluorescence intensity at individual boutons were obtained by averaging the pixel intensities of the selected area using ImageJ. Individual regions were selected by hand and regions of interest were drawn around the synaptic boutons, then average intensities were calculated. Large puncta which typically represent clusters of smaller synapses were rejected during the selection process. The center of each synapse was calculated to compensate for any image shift over the course of the experiment. Fluorescence was expressed in intensity units that correspond to fluorescence values averaged over all pixels within the region of interest. Net fluorescence changes, for individual boutons, were obtained by subtracting the average intensity of the first four frames $\left(F_{0}\right)$ from the intensity of each frame $\left(F_{t}\right)$. They were then normalized to the maximum fluorescence intensity $\left(F_{\max }-F_{0}\right)$ and averaged. All fitting was done using individual error bars to weight the fit using Origin Pro 9.0 (Origin Lab Corporation, Northampton, MA). To obtain the endocytic time constant after stimulation, the decay of $\mathrm{pH}$-probe after stimulation was fitted with a single exponential function. Data were collected from $\sim 140$ boutons of 12-24 neurons in each coverslip and " $n$ " stands for the number of coverslips. Statistical analysis was performed with GraphPad Prism 7.0 (GraphPad Software, San Diego, CA). Once the normality assumption was satisfied, two independent groups were compared by Student's two sample $t$-test.

\section{Surface fraction measurement}

For a surface fraction of Syt1-pHluorin measurement cultured hippocampal neurons were transfected with mRFP-tagged shRNA targeting SGIP1 $\alpha$ or scrambled RNA and Syt1-pHluroin. Transfected neurons were mounted in closed perfusion/stimulation chamber (LCI) and perfused continuously with standard $\mathrm{pH} 7.4$ tyrode solution or non-permeable pH 5.5 acid solution at RT by using MPS-8-multi-valve perfusion system (LCI) at 0.5 $\mathrm{mL} / \mathrm{min} .300$ action potentials (APs) at $10 \mathrm{~Hz}$ were applied using platinum-iridium electrodes and A310 Accupulser current stimulator (World Precision Instruments). Fluorescent images of Syt1-pHluorin were acquired at every $5 \mathrm{~s}$ and analyzed using ImageJ through marking individual rectangular regions of interest (ROIs) by hand.

\section{Modeling of crystal structures and multiple sequence alignments}

Ribbon models of the crystal structures were obtained from SWISS-MODEL https://swissmodel.expasy.org/ Accessed 23 July 2018 [32]. Multiple protein sequence alignments were performed using the Constraint-based Multiple Alignment Tool https://www.ncbi.nlm.nih.gov/tools/cobalt/ Accessed 3 March 2019.

\section{Results}

The previous study has identified SGIP1 $\alpha$ as a brain-specific longest isoform of SGIP1 [23], and we first analyzed the expression of SGIP1 $\alpha$ in primary cultured rat hippocampal neurons. Since there is no specific antibody that distinguishes SGIP1 $\alpha$ from SGIP1, we compared the size of endogenous SGIP1 $\alpha$ in hippocampal neurons with that of FLAG-tagged SGIP1 $\alpha$ or SGIP1 transfected in the HEK293T cells with a commercial antibody against SGIP1. We found that hippocampal neurons endogenously expressed a protein with a molecular mass of about $130 \mathrm{kDa}$, which was comparable to 
the size of FLAG-tagged SGIP1 $\alpha$ but higher than that of FLAG-tagged SGIP1 in HEK293T (Fig. 1b). These results suggest that SGIP1 $\alpha$, not SGIP1 is endogenously expressed in hippocampal neurons.

\section{SGIP1a physically interacts with Syt1}

To identify the binding partners of SGIP1 $\alpha$ in neurons, we performed GST-pull down assay. The purified GST-tagged SGIP1 $\alpha$ were incubated with rat hippocampal neuron lysates. Fraction bound or unbound with SGIP1 $\alpha$ were resolved by SDS-PAGE and stained with Coomassie blue. Multiple bands with varying molecular weights were detected although some of them appeared to be non-specific when we compared them to bands in GST-SGIP1 $\alpha$ lane (the lane without neuron lysate; Fig. 1c). Four bands were identified as specific, which include one at $130 \mathrm{kDa}$ (which seems to be EPS15 [29]), two around $65 \mathrm{kDa}$ and one below $55 \mathrm{kDa}$ (Fig. 1c). Given the proposed role in endocytosis and brain-specific expression pattern, we reasoned that SGIP1 $\alpha$ could interact with a presynaptic protein expressed in SVs. We noticed a particular band around $65 \mathrm{kDa}$ since we are aware that the prominent SV resident protein, Syt1 has a molecular weight of $60 \sim 70 \mathrm{kDa}$. Indeed, the band was confirmed as Syt1 by western blot with a specific antibody against Syt1 (Fig. 1c).

To find out which domain of SGIP1 $\alpha$ interacts with Syt1, we looked the published literatures up and found that Syt1 interacts with the $\mu \mathrm{HD}$ of AP-2 via its $\mathrm{C} 2$ domains $[33,34]$. Since SGIP1 $\alpha$ also contains $\mu H D$, it would be the domain most likely to interact with Syt1. Indeed, when the same experiment was performed with $\mu \mathrm{HD}$ of SGIP1 $\alpha$, the band with identical size was detected thus indicating that SGIP1 $\alpha$ binds with endogenous Syt1 via its $\mu \mathrm{HD}$.

To corroborate the association of SGIP1 $\alpha$ with Syt1, we conducted GST-pull down assay experiments. The GST-fused cytoplasmic (C2AB) domains of Syt1 were purified and incubated with the transfected HEK293T lysates. As shown in Fig. 1e, HA-tagged SGIP1 $\alpha$ bound to the $\mathrm{C} 2 \mathrm{AB}$ fusion protein while it did not bind to GST control beads. When the same experiment was carried out with $\mu \mathrm{HD}$ (aa 550-854) and $\Delta \mu \mathrm{HD}$ domain (aa 1549 ) of SGIP $1 \alpha$, the only $\mu \mathrm{HD}$ bound to $\mathrm{C} 2 \mathrm{AB}$, suggesting the interaction between $\mathrm{C}$-terminal $\mu \mathrm{HD}$ domain of SGIP1 $\alpha$ and C2 domains of Syt1.

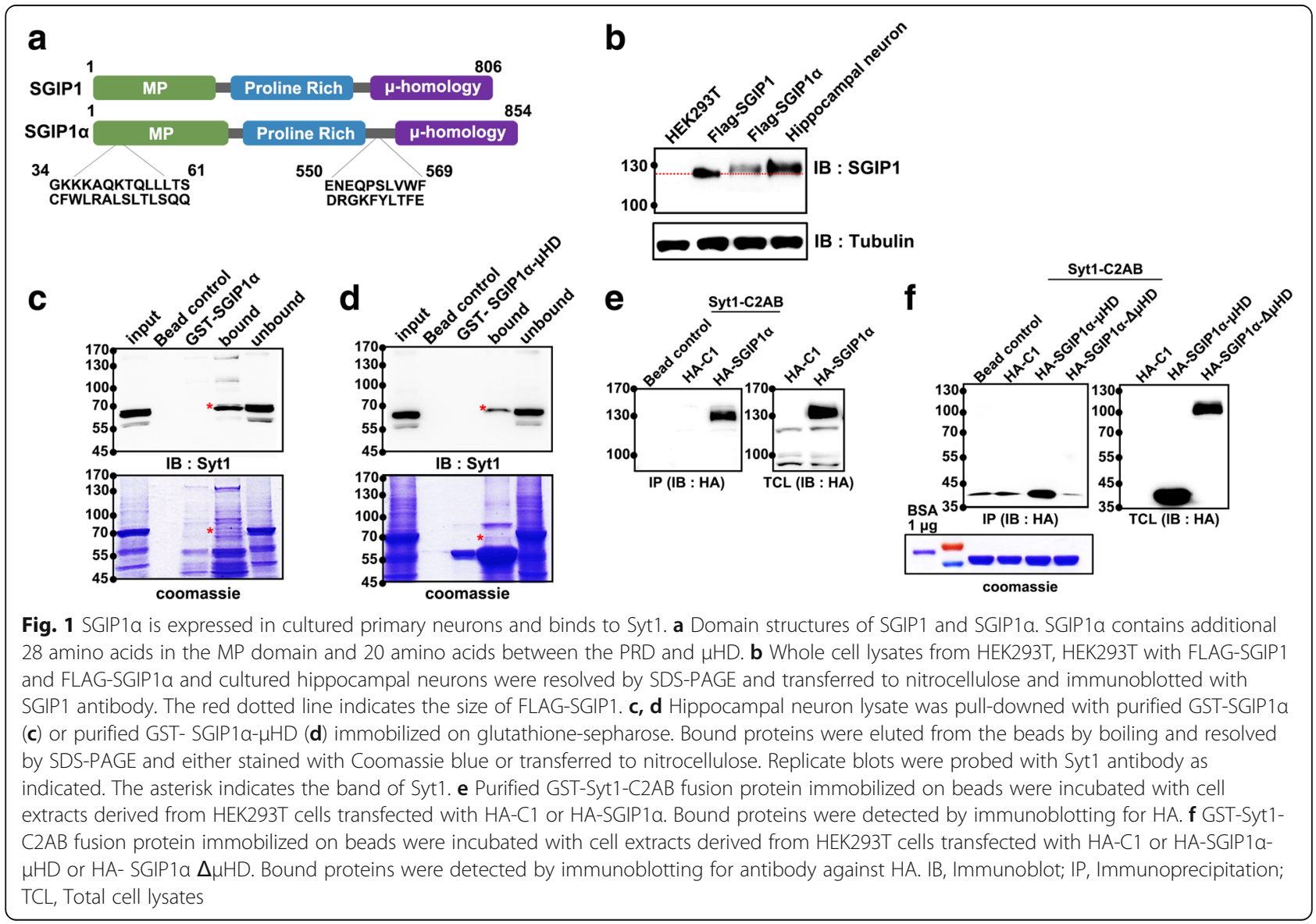


To gain insight into the possible function of SGIP1 $\alpha$ in hippocampal neurons, we immunostained primary cultured hippocampal neurons at DIV 21 with specific antibodies against endogenous SGIP1 $\alpha$ and Syt1. Consistent with their physical association, approximately $76 \%$ of SGIP1 $\alpha$ colocalized with Syt 1 at synapses in cultured neurons (Fig. $2 \mathrm{a}$ and b). The experiment revealed that neuronal-specific isoform SGIP1 $\alpha$ is expressed in the presynaptic terminals of primary cultured neurons where it colocalizes with Syt1.

SGIP1a KD selectively impairs the internalization of Syt1 but not synaptophysin or VAMP 2 from the neuronal surface To assess the physiological effects of SGIP1 $\alpha$, we generated an AAV-shRNA construct targeting SGIP1 $\alpha$.
Suppression of SGIP1 $\alpha$ expression level by shRNA was confirmed by western blot analysis of AAV-shRNA infected cultured cortical neurons (Fig. $2 \mathrm{c}$ and d).

In primary cultured hippocampal neurons, SV proteins including Syt1 are constitutively recycled between SVs and the presynaptic plasma membrane. To quantitatively estimate the trafficking of Syt1 between vesicular and plasma pools, we used Syt1-pHluorin, which is a fusion construct between the luminal domain of Syt1 and pHluorin, a modified GFP with high pH sensitivity [35-37] such that its fluorescence is quenched in acidic conditions and increased in basic conditions upon exocytosis to the extracellular space. The exocytosis was evoked by applying $10 \mathrm{~Hz}$ field stimulus for $30 \mathrm{~s}$. The Syt1-pHluorin fluorescence intensity of the individual boutons increased rapidly and decayed
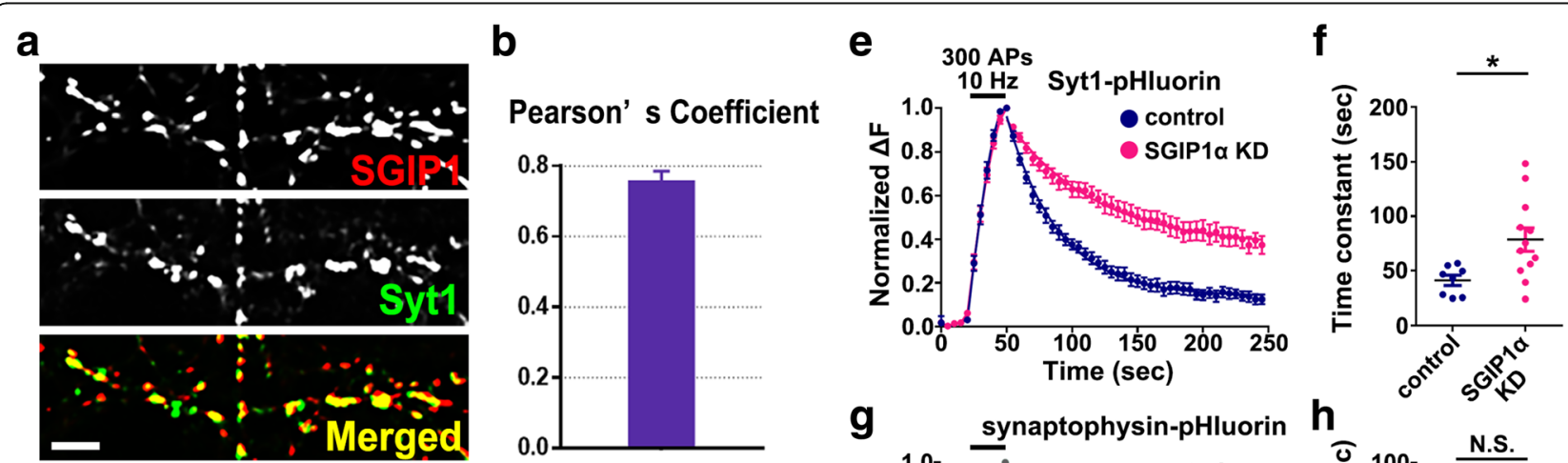

C
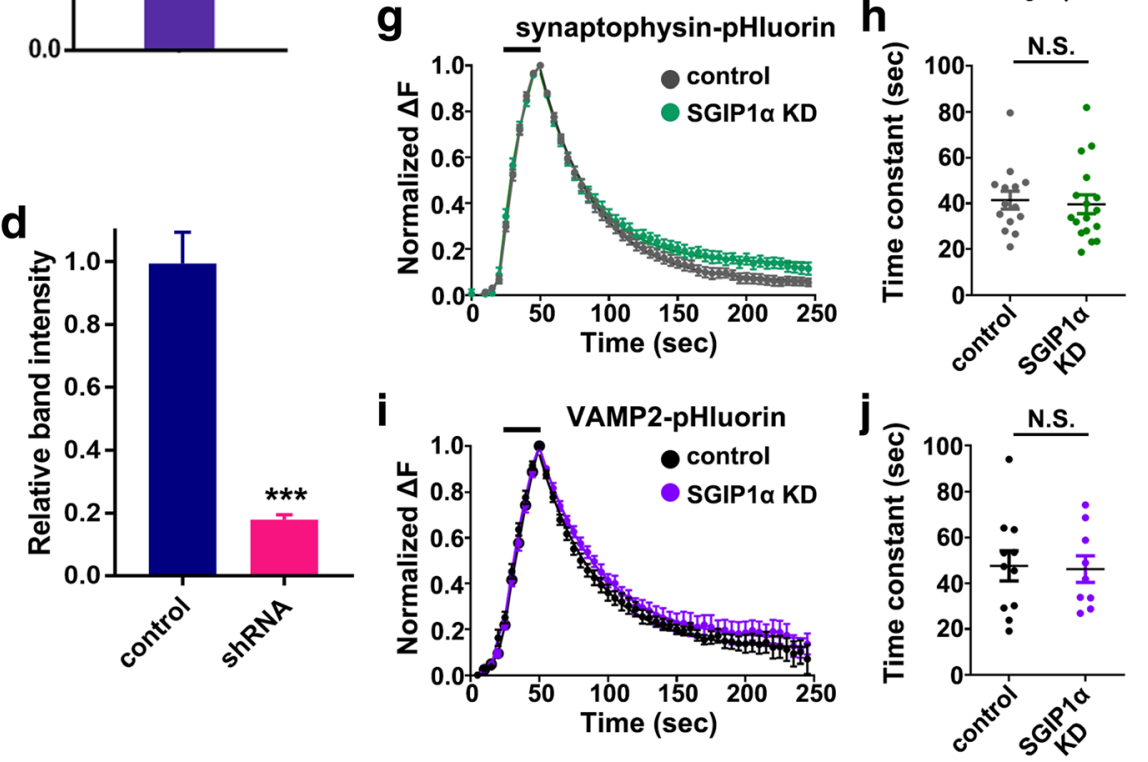

Fig. 2 SGIP1a is expressed at the presynaptic terminals of cultured hippocampal neurons and SGIP1a KD causes the selective defects in the internalization of Syt1. a Rat brain hippocampal neurons were fixed at DIV 21 and immunostained with specific antibodies against SGIP1a (red) and Syt1 (green). Scale bar, $5 \mu \mathrm{m}$. b Pearson's coefficient of colocalization between SGIP1a and Syt1 $(n=10)$. (c and d) Primary cultured neurons at DIV 6 were infected with AAV-shRNA-SGIP1a, and the KD efficiency was confirmed by western blotting with anti-SGIP1 antibody at DIV 21 ( $n=$ 3 blots). e-j Average Syt1-pHluorin (e, control: $n=8, \mathrm{KD}: n=12$ ), synaptophysin-pHluorin (g, control: $n=14$, KD: $n=17$ ), or VAMP2-pHluorin (I, control: $n=11, \mathrm{KD}: n=19)$ fluorescence intensity profiles in neurons expressing empty vector or shRNA-SGIP1a, plotted as $\Delta F / F_{0}$ against time, after stimulation with $300 \mathrm{APs}$ at $10 \mathrm{~Hz}$ (dark bar). Fluorescence values were normalized to the maximal fluorescence signal in each experimental

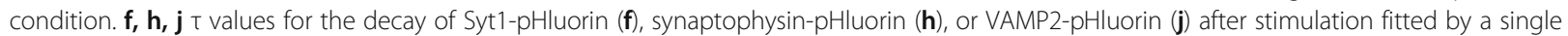
exponential. Data are means \pm SEM; ${ }^{*} p<0.05,{ }^{* *} p<0.001$ by Student's t-test, N.S., not significant 
after reaching a peak with an exponential time course, revealing the kinetics of endocytosis.

We found that in SGIP1 $\alpha$ KD boutons, Syt1 endocytosis was significantly slowed with a longer time constant than in control boutons $(\tau=41.25 \pm 4.67 \mathrm{~s}$ for the control; $\tau=78.63 \pm 10.76 \mathrm{~s}$ for SGIP1 $\alpha \mathrm{KD}$; Fig. $2 \mathrm{c}$ e and $\mathrm{f}$ ). When we repeated endocytosis assays using other SV proteins, synaptophysin (Fig. 2 g and h) or VAMP2 (Fig. 2) $\mathrm{i}$ and $\mathrm{j}$, however, no endocytic defects were observed (synaptophysin-pHluorin: $\tau=41.44 \pm 3.91 \mathrm{~s}$ for the control; $\tau=39.63 \pm 4.12 \mathrm{~s}$ for SGIP1 $\alpha$ KD; VAMP2-pHluorin: $\mathrm{\tau}=$ $47.57 \pm 6.58 \mathrm{~s}$ for the control; $\tau=46.17 \pm 5.85 \mathrm{~s}$ for SGIP $1 \alpha$ KD). These results suggest that SGIP1 $\alpha$ KD hinders the endocytosis of Syt1, but not synaptophysin or VAMP2.

We then quantitatively analyzed the effect of SGIP1 $\alpha$ KD on the partitioning of Syt1 between the presynaptic plasma membrane and internal SV pool in primary hippocampal neurons (Fig. 3). To assess the surface and vesicular pools of Syt1-pHluorin under steady state and stimulating conditions, the relative fluorescence values were quantitatively measured using the acid quenching-dequenching protocol [11] before and after stimulation with 300 APs (Fig. 3 a). We found that under resting conditions, SGIP1 $\alpha$ KD did not induce a significant change in the relative plasma membrane to the vesicle fraction of Syt1 (Fig. $3 \mathrm{a}$ and b). However, the relative plasma membrane fraction of Syt1-pHluorin at presynaptic boutons increased significantly after stimulation with 300 APs (Fig. 3 a and c). These results indicated that the surface stranded portion of Syt1 is increased only after stimulation but not under resting conditions in KD neurons.

\section{Structural similarity of SGIP1a $\mu \mathrm{HD}$ with those of AP- $2 \mu$ and stonin2}

The $\mu \mathrm{HD}$ is an $\sim 280$ amino acid residue protein-protein interaction module found in endocytic proteins involved in CME such as AP complexes, stonins, and proteins of the muniscin family including Syp1, $\mathrm{FCHO} 1 / 2$, and SGIP1 [26, 27, 38]. The $\mu \mathrm{HD}$ of the muniscin proteins is involved in the interactions with the endocytic adaptorscaffold proteins Ede1-Eps15 [38]. We observed that SGIP1 $\alpha$ associates with the Syt 1 C 2 domains via its $\mu \mathrm{HD}$ (Fig. 1f). To further delineate the interaction between $\mu \mathrm{HD}$ of SGIP1 and Syt1, we generated a molecular homology model of SGIP1 $\alpha \mu \mathrm{HD}$ using AP- $2 \mu$ and stonin2$\mu \mathrm{HD}$ as templates.

SGIP1 $\alpha \mu \mathrm{HD}$ displays an overall $\beta$-fold structure very similar to that of AP- $2 \mu$ and stonin $2-\mu \mathrm{HD}$ (Fig. 4 a). The $\beta$ strand is suggested to harbor the Syt1 binding site with AP- $2 \mu$ containing bulky aromatic residue. SGIP1 $\alpha$ also has a bulky aromatic tryptophan residue, Trp771, which corresponds to Tyr344 in AP- $2 \mu$, and Tyr784 in human stonin2 (Fig. 4 b). Indeed, Trp771, as well as several flanking residues, is also evolutionarily conserved within SGIP1 family members of vertebrates, suggesting

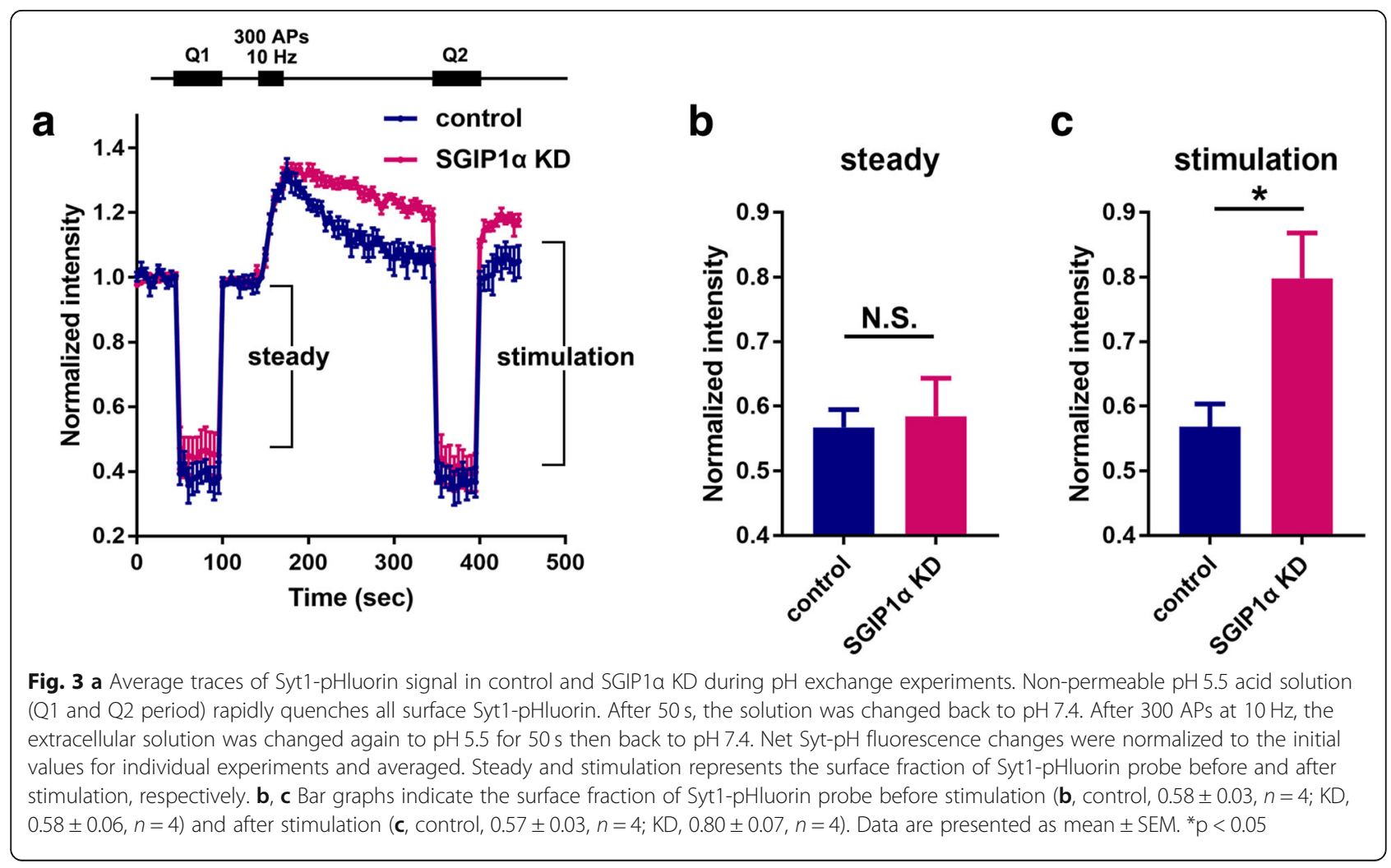




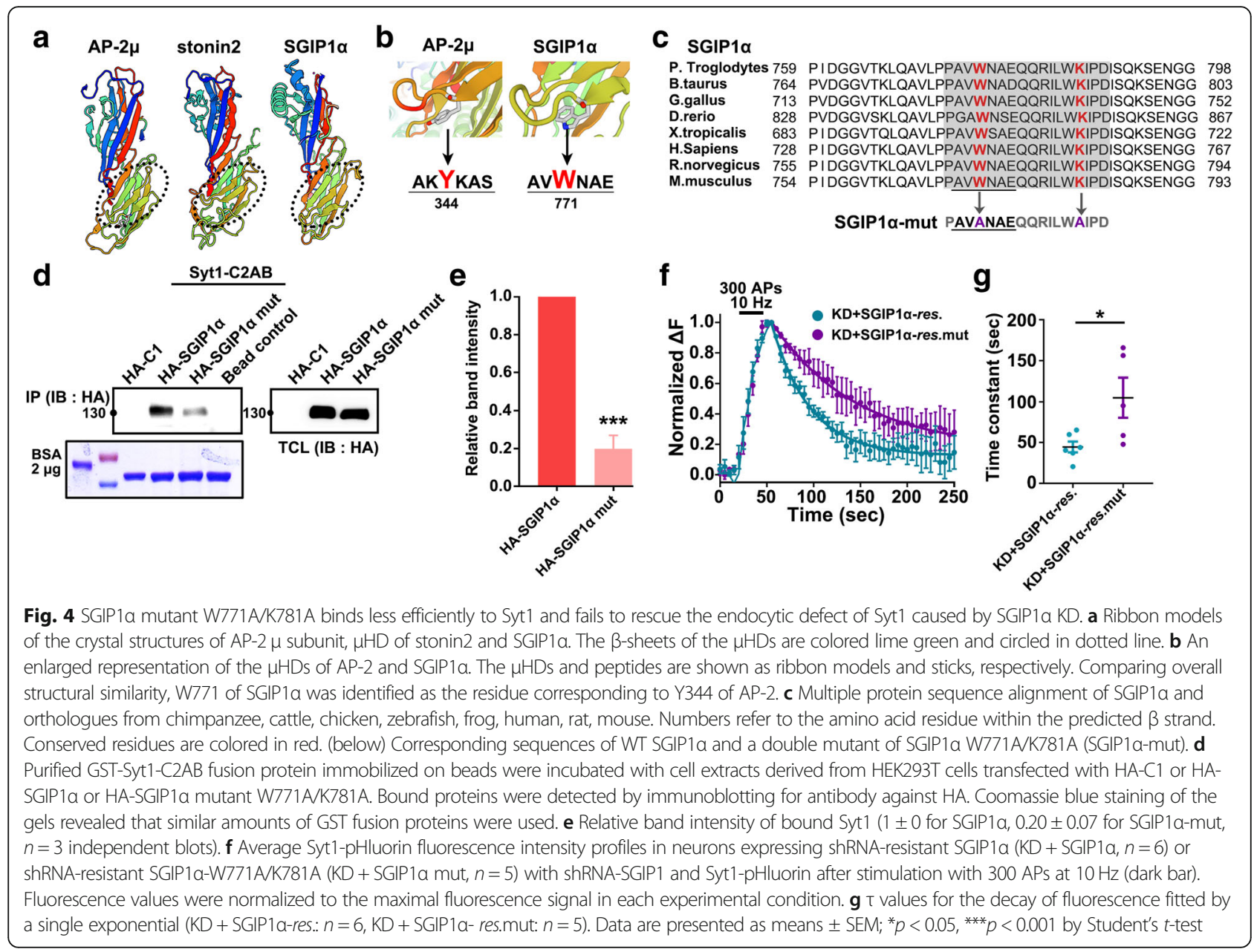

its functional importance (Fig. $4 \mathrm{c}$ ). Thus, it could be the residue that has Syt1 binding affinity.

\section{SGIP1a mutant W771A/K781A binds less efficiently to Syt 1 and fails to rescue the endocytic defect of Syt 1 by SGIP1a KD}

The previous study found that Tyr344A/Lys354A mutant of AP- $2 \mu$ bound less efficiently to Syt1 than wild-type (WT) ( 20\% of WT) [33]. Given the homology between AP-2 $\mu$ and SGIP1 $\alpha \mu \mathrm{HD}$, we hypothesized that a double mutant of SGIP1 $\alpha$, in which Trp771 and Lys781 that correspond to Tyr344 and Lys354 of AP-2 $\mu$ mutated to alanine (Fig. $4 \mathrm{c}$ ), would have a lower affinity for Syt1. We transfected HEK293T with SGIP1 $\alpha$ or a W771A/K781A mutant and performed GST-pull down experiments using GST-fused Syt1. As expected, the affinity of W771A/ K781A mutant for Syt1-C2AB was substantially reduced compared to that of the WT SGIP1 $\alpha$ (Fig. $4 \mathrm{~d}$ and e).

We then expressed the shRNA-resistant form of SGIP1 $\alpha$ or its $\mathrm{W} 771 \mathrm{~A} / \mathrm{K} 781 \mathrm{~A}$ mutant under the conditions of SGIP1 $\alpha$ KD to test whether it could rescue KD-mediated defects in Syt1 internalization. We found that SGIP1 $\alpha$ WT completely rescued the defects in Syt1 internalization, but the W771A/K781A mutant did not $(\tau=44.59 \pm 6.60 \mathrm{~s}$ for the WT over SGIP1 KD; $\tau=104.8 \pm 24.32 \mathrm{~s}$ for SGIP1 $\alpha \mathrm{mu}-$ tant over KD; Fig. 4 e and f). These results ultimately suggest that the Trp771/Lys781 residues in the $\mu \mathrm{HD}$ of SGIP1 $\alpha$ are critical for the binding and internalization of Syt1.

\section{Discussion}

In this study, we provide multiple experimental evidence for a cargo-selective role of SGIP1 $\alpha$ in the retrieval of Syt1 on the neuronal surface. Besides its originally identified function as a candidate gene for regulating energy balance and potentially important in determining obesity risk in humans $[21,22]$, several studies have also found that SGIP1 is an endocytic protein that functions as the molecular interface between the basic machinery of endocytosis and components of actin cytoskeletal rearrangements [23, 24]. More recently, a brain-specific and the longest splicing variant SGIP1 $\alpha$ has been identified and it is known to play an essential role in CME by 
interacting with the Eps15 and AP-2 complexes as well as by deforming the plasma membrane [23]. Its functional significance especially during SV recycling, however, has not been studied.

Regardless of the endocytosis mode, the newly retrieved SVs should contain essential SV proteins with the correct stoichiometry that can be functional for the next round of exocytosis. Various adapter proteins that selectively recognize individual cargoes recruit SV proteins to the newly created SVs [6]. These adapters can bind directly to cargo proteins and recruit clathrin coat proteins at the same time. Some SV cargoes, such as vGlut1, VAMP2, and Syt1, contain several retrieval motifs that are recognized by multiple different adapter proteins [39]. As the SV membrane is reformed at various rates through different modes depending on neural activity, a "safeguard" system with multiple motifs in individual cargoes definitely help to maintain the exact stoichiometry of the essential SV cargoes required per SV [39]. On this account, a distinct pathway for SV recycling called kiss-and-run has been proposed as an alternative endocytic mode in neurons to satisfy the sorting accuracy at the appropriate rate of exo-endocytosis [40].

As a major $\mathrm{Ca}^{2+}$ sensor for $\mathrm{SV}$ exocytosis, Syt1 should be incorporated into SVs during endocytosis. Previous studies have shown that stonin2 recognizes the basic patch within the Syt1 C2 domains and interacts with Syt1 to facilitate sorting of Syt1 into retrieved SVs [11, 37]. Nevertheless, another study suggested that Syt1 mutants with reduced affinity for stonin 2 are still internalized, suggesting that additional determinants and/or cooperative effects may be involved [37]. Indeed, the loss of other SV protein, SV2A/B, in mice is known to cause the defects in sorting Syt1 [20, 41]. SV2A/B deficiency impairs the efficacy of stimulation-evoked SV exocytosis, a phenotype associated with the loss of Syt1 in SVs [11]. Interestingly, the combined deficiency of SV2A/B and stonin2 causes additive defects in Syt1 sorting at the synapses [19], thus despite their distinct molecular features, they appear to perform a shared overlapping function on sorting of Syt1 in synapses. In this study, we found that SGIP1 $\alpha$ is another selective sorting adaptor for endocytic internalization and recycling of Syt1. Our result showed that SGIP1 $\alpha$ is not required for the retrieval of other SV proteins, synaptophysin or VAMP2 (Fig. 2), which is consistent with the previous study in which SV2A/B deficiency selectively impairs endocytic retrieval of Syt1 rather than synaptophysin [19].

It is noteworthy that the endocytosis of Syt1 is partially but not completely impaired in SGIP $1 \alpha$ depleted neurons (Fig. 2 e and f). Indeed, the previous study also showed that deletion or KD of either SV2A/B or stonin2 results in partial missorting of Syt1 to the neuronal surface, implying the existence of functional redundancy among related proteins. Functional redundancy in a set of proteins is not rare in nervous system, especially in the SV recycling process. It could provide a protective mechanism to prevent a life-threatening disaster from happening even if only one protein is depleted. In addition, considering the fact that a single SV contains multiple copies of Syt1 (15.2 copies/vesicle) [4], we believe that SGIP1 $\alpha$ together with SV2A/B and stonin2 may play compensatory function, rather than compete for the trafficking of Syt. We, however, cannot fully rule out the possibility in which these three proteins may function in Syt1 retrieval process at distinct steps or different activity states. In fact, the direct binding of Syt 1 to AP-2 is $\mathrm{Ca}^{2+}$-dependent while stonin2 bind to Syt1 in a $\mathrm{Ca}^{2+}$-independent manner. Furthermore, the $\mathrm{N}$-terminus of SV2A is required for binding to the C2B domain of Syt1 but whether this binding is $\mathrm{Ca}^{2+}$-dependent or not is currently unclear [42]. Therefore, although AP-2, stonin2 and $\mathrm{SV} 2 \mathrm{~A} / \mathrm{B}$ all bind to the $\mathrm{C} 2$ domains of Syt1, their $\mathrm{Ca}^{2+}$-dependency for binding seem different. Whether SGIP1 $\alpha$ bind to Syt1 in a $\mathrm{Ca}^{2+}$-dependent manner or not would certainly be of interest.

We further found the structural similarity between $\mu \mathrm{HD}$ of SGIP1 $\alpha$ with those of stonin 2 and AP-2 and showed their functional similarity within the corresponding residues (Fig. $4 \mathrm{a}$ and b). We demonstrated that Trp771 residue within the $\beta$ strand in the $\mu \mathrm{HD}$ of SGIP1 $\alpha$ corresponds to the Syt1-binding Tyr344 of AP- $2 \mu$ or Tyr784 of stonin2. Evidently, a double mutant of Trp771A/Lys781A of SGIP1 $\alpha$ not only showed reduced ability to bind to Syt1 but also could not restore the defects of Syt1 retrieval by SGIP1 KD (Fig. $4 \mathrm{~d}$ to g).

SV release occurs at several modes that are dependent (synchronous, asynchronous) or independent (spontaneous) on APs. Syt1 functions as a $\mathrm{Ca}^{2+}$ sensor at the synchronous mode, but the $\mathrm{Ca}^{2+}$ sensor has not been identified at the other two modes. A recent study found that the cytoplasmic protein known as Doc2 (double C2 domain) is required for spontaneous release and promotes membrane fusion in response to an exceptionally low increase in $\mathrm{Ca}^{2+}$ [43]. Doc2 is more sensitive to $\mathrm{Ca}^{2+}$ and competes with Syt1 for SNARE-complex binding during membrane fusion, thus acting as a high-affinity $\mathrm{Ca}^{2+}$ sensor for spontaneous release [43]. Therefore, in the presence of Doc2, normal spontaneous release and unaltered steady state SV recycling could be maintained even under SGIP1 $\alpha$ depleted condition. In addition, Syts constitute a family of proteins and in vertebrates, 16 isoforms of Syt have been identified [44]. Besides the most abundant isoform Syt1, Syt2 is also localized to SVs and function as a $\mathrm{Ca}^{2+}$-sensor although they are differentially expressed in a largely non-overlapping pattern [34, 45, 46]. Other Syts including Syt3, 6 and 7 are also known to perform complementary functions in exocytosis. Whether 
SGIP1 $\alpha$ interacts with Doc2 or other Syt isoforms in a manner different from Syt1 is certainly a matter of interest and further study is needed.

Together, our data clearly demonstrate that SGIP1 $\alpha$ functions as a selective adaptor for Syt1 for its endocytic retrieval and sorting into SVs. Thus we propose the compensatory fail-safe mechanism in which SGIP1 $\alpha$ joins a group of proteins with stonin2 and SV2A/B, allowing synapses to ensure the accurate sorting of Syt1 for subsequent neurotransmission.

\section{Abbreviations}

APs: Action potentials; AP-V: DL-2-amino-5-phosphonovaleric acid; AZ: Active zone; BCA: Bicinchoninic acid; BSA: Bovine serum albumin; $\mathrm{Ca}^{2+}$ : Calcium; CME: Clathrin-mediated endocytosis; CNQX: 6-cyano-7-nitroquinoxaline-2,3dione; DIV: Days in vitro; F: Fluorescence; FCHo: Fer/Cip4 homology domainonly; HBSS: Hank's Balanced Salt Solution; HEK: Human embryonic kidney; IACUC: Institute of animal care and use committee; IB: Immunoblot; IP: Immunoprecipitation; KD: Knock-down; KO: Knock-out; LB: Luria-Bertani; PVDF: Polyvinylidene difluoride; RNAi: RNA interference; ROIs: Regions of interest; RT: Room temperature; SGIP1: SH3-containing GRB2-like protein 3interacting protein 1; shRNA: small hairpin RNA; SV: Synaptic vesicle; SV2A/ B: Synaptic Vesicle Glycoprotein 2A/B; Syt1: Synaptotagmin 1; TCL: Total cell lysates; VAMP2: Vesicle associated membrane protein 2; vGlut1: Vesicular glutamate transporter $1 ; \mu \mathrm{HD}: \mu$-homology domain

\section{Acknowledgments}

We are grateful to the Biomedical Imaging Center at Seoul National University College of Medicine for microscope services.

\section{Funding}

This work was supported by the Intensive Development Research Project of Seoul National University Hospital (03-2018-0240) to SC and the Education and Research Encouragement Fund of SNUH. This research was also supported by grants from the Brain Research Program (NRF-

2017M3C7A1044958 and 2015M3C7A1028790) to SC through the National Research Foundation of Korea, Republic of Korea.

\section{Availability of data and materials}

All data generated or analyzed during this study are included in this published article.

The datasets used and/or analyzed during the current study are available from the corresponding author on reasonable request.

\section{Authors' contributions}

S-EL and SC designed the experiments. S-EL, SJ and UL performed the experiments. S-EL, UL and SC analyzed the data and S-EL and SC wrote the paper. All authors read and approved the final manuscript.

\section{Ethics approval and consent to participate}

All of the animal experiments were performed in accordance with the guidelines set by the Institute of Animal Care and Use Committee (IACUC) of Seoul National University, Korea.

\section{Consent for publication}

Not applicable.

\section{Competing interests}

The authors declare that they have no competing interests.

\section{Publisher's Note}

Springer Nature remains neutral with regard to jurisdictional claims in published maps and institutional affiliations.
Received: 7 March 2019 Accepted: 16 April 2019

Published online: 03 May 2019

\section{References}

1. Jahn R, Scheller RH. SNAREs--engines for membrane fusion. Nat Rev Mol Cell Biol. 2006;7(9):631-43.

2. Kononenko NL, Haucke V. Molecular mechanisms of presynaptic membrane retrieval and synaptic vesicle reformation. Neuron. 2015;85(3):484-96.

3. Cousin MA. Integration of synaptic vesicle cargo retrieval with endocytosis at central nerve terminals. Front Cell Neurosci. 2017;11:234.

4. Takamori S, Holt M, Stenius K, Lemke EA, Gronborg M, Riedel D, et al. Molecular anatomy of a trafficking organelle. Cell. 2006;127(4):831-46.

5. Kononenko NL, Diril MK, Puchkov D, Kintscher M, Koo SJ, Pfuhl G, et al. Compromised fidelity of endocytic synaptic vesicle protein sorting in the absence of stonin 2. Proc Natl Acad Sci U S A. 2013;110(6):E526-35.

6. Saheki Y, De Camilli P. Synaptic vesicle endocytosis. Cold Spring Harb Perspect Biol. 2012;4(9):a005645.

7. Traub LM, Bonifacino JS. Cargo recognition in clathrin-mediated endocytosis. Cold Spring Harb Perspect Biol. 2013;5(11):a016790.

8. Granseth B, Odermatt B, Royle SJ, Lagnado L. Clathrin-mediated endocytosis is the dominant mechanism of vesicle retrieval at hippocampal synapses. Neuron. 2006:51(6):773-86.

9. Koo SJ, Kochlamazashvili G, Rost B, Puchkov D, Gimber N, Lehmann M, et al. Vesicular Synaptobrevin/NAMP2 levels guarded by AP180 control efficient neurotransmission. Neuron. 2015;88(2):330-44.

10. Vanlandingham PA, Barmchi MP, Royer S, Green R, Bao H, Reist N, et al. AP180 couples protein retrieval to clathrin-mediated endocytosis of synaptic vesicles. Traffic. 2014;15(4):433-50.

11. Diril MK, Wienisch M, Jung N, Klingauf J, Haucke V. Stonin 2 is an AP-2dependent endocytic sorting adaptor for synaptotagmin internalization and recycling. Dev Cell. 2006;10(2):233-44.

12. Martina JA, Bonangelino CJ, Aguilar RC, Bonifacino JS. Stonin 2: an adaptorlike protein that interacts with components of the endocytic machinery. J Cell Biol. 2001;153(5):1111-20.

13. Willox AK, Royle SJ. Stonin 2 is a major adaptor protein for clathrinmediated synaptic vesicle retrieval. Curr Biol. 2012;22(15):1435-9.

14. Walther $K$, Diril MK, Jung N, Haucke V. Functional dissection of the interactions of stonin 2 with the adaptor complex AP-2 and synaptotagmin. Proc Natl Acad Sci U S A. 2004;101(4):964-9.

15. Feany MB, Yee AG, Delvy ML, Buckley KM. The synaptic vesicle proteins SV2, synaptotagmin and synaptophysin are sorted to separate cellular compartments in CHO fibroblasts. J Cell Biol. 1993;123(3):575-84.

16. Kaempf N, Maritzen T. Safeguards of neurotransmission: Endocytic adaptors as regulators of synaptic vesicle composition and function. Front Cell Neurosci. 2017;11:320

17. Geppert M, Goda Y, Hammer RE, Li C, Rosahl TW, Stevens CF, et al. Synaptotagmin-I - a major Ca2+ sensor for transmitter release at a central synapse. Cell. 1994;79(4):717-27.

18. Mackler JM, Drummond JA, Loewen CA, Robinson IM, Reist NE. The C2BCa2 +- binding motif of synaptotagmin is required for synaptic transmission in vivo. Nature. 2002;418(6895):340-4.

19. Kaempf N, Kochlamazashvili G, Puchkov D, Maritzen T, Bajjalieh SM, Kononenko NL, et al. Overlapping functions of stonin 2 and SV2 in sorting of the calcium sensor synaptotagmin 1 to synaptic vesicles. Proc Natl Acad Sci U S A. 2015;112(23):7297-302.

20. Yao J, Nowack A, Kensel-Hammes P, Gardner RG, Bajjalieh SM. Cotrafficking of SV2 and Synaptotagmin at the synapse. J Neurosci. 2010;30(16):5569-78.

21. Trevaskis J, Walder K, Foletta V, Kerr-Bayles L, McMillan J, Cooper A, et al. Src homology 3-domain growth factor receptor-bound 2-like (endophilin) interacting protein 1, a novel neuronal protein that regulates energy balance. Endocrinology. 2005;146(9):3757-64.

22. Cummings N, Shields KA, Curran JE, Bozaoglu K, Trevaskis J, Gluschenko K, et al. Genetic variation in SH3-domain GRB2-like (endophilin)-interacting protein 1 has a major impact on fat mass. Int J Obes. 2012;36(2):201-6.

23. Uezu A, Horiuchi A, Kanda K, Kikuchi N, Umeda K, Tsujita K, et al. SGIP1alpha is an endocytic protein that directly interacts with phospholipids and Eps15. J Biol Chem. 2007:282(36):26481-9.

24. Henne WM, Boucrot E, Meinecke M, Evergren E, Vallis Y, Mittal R, et al. FCHo proteins are nucleators of clathrin-mediated endocytosis. Science. 2010; 328(5983):1281-4 
25. Hollopeter G, Lange JJ, Zhang Y, Vu TN, Gu M, Ailion M, et al. The membrane-associated proteins FCHo and SGIP are allosteric activators of the AP2 clathrin adaptor complex. eLife 2014;3:e03648 DOl: https://doi.org/ 10.7554/eLife.03648.

26. Umasankar PK, Ma L, Thieman JR, Jha A, Doray B, Watkins SC, et al. A clathrin coat assembly role for the muniscin protein central linker revealed by TALEN-mediated gene editing. elife. 2014;3:e04137 DOI: https://doi.org/ 10.7554/eLife.04137.

27. Shimada A, Yamaguchi A, Kohda D. Structural basis for the recognition of two consecutive mutually interacting DPF motifs by the SGIP1 mu homology domain. Sci Rep. 2016;6:19565.

28. Tsujita K, Suetsugu S, Sasaki N, Furutani M, Oikawa T, Takenawa T. Coordination between the actin cytoskeleton and membrane deformation by a novel membrane tubulation domain of $\mathrm{PCH}$ proteins is involved in endocytosis. J Cell Biol. 2006;172(2):269-79.

29. Fazioli F, Minichiello L, Matoskova B, Wong WT, Di Fiore PP. eps15, a novel tyrosine kinase substrate, exhibits transforming activity. Mol Cell Biol. 1993;13(9):5814-28.

30. Dergai O, Novokhatska O, Dergai M, Skrypkina I, Tsyba L, Moreau J, et al. Intersectin 1 forms complexes with SGIP1 and Reps1 in clathrin-coated pits. Biochem Biophys Res Commun. 2010;402(2):408-13.

31. Chang S, De Camilli P. Glutamate regulates actin-based motility in axonal filopodia. Nat Neurosci. 2001;4(8):787-93.

32. Waterhouse A, Bertoni M, Bienert S, Studer G, Tauriello G, Gumienny R, et al. SWISS-MODEL: homology modelling of protein structures and complexes. Nucleic Acids Res. 2018;46(W1):W296-303.

33. Haucke V, Wenk MR, Chapman ER, Farsad K, De Camilli P. Dual interaction of synaptotagmin with mu2- and alpha-adaptin facilitates clathrin-coated pit nucleation. EMBO J. 2000;19(22):6011-9.

34. Ullrich B, Li C, Zhang JZ, McMahon H, Anderson RG, Geppert M, et al. Functional properties of multiple synaptotagmins in brain. Neuron. 1994; 13(6):1281-91.

35. Fernandez-Alfonso T, Kwan R, Ryan TA. Synaptic vesicles interchange their membrane proteins with a large surface reservoir during recycling. Neuron. 2006;51(2):179-86.

36. Hua Y, Sinha R, Thiel CS, Schmidt R, Huve J, Martens H, et al. A readily retrievable pool of synaptic vesicles. Nat Neurosci. 2011;14(7):833-9.

37. Jung N, Wienisch M, Gu M, Rand JB, Muller SL, Krause G, et al. Molecular basis of synaptic vesicle cargo recognition by the endocytic sorting adaptor stonin 2. J Cell Biol. 2007:179(7):1497-510

38. Reider A, Barker SL, Mishra SK, Im YJ, Maldonado-Baez L, Hurley JH, et al. Syp1 is a conserved endocytic adaptor that contains domains involved in cargo selection and membrane tubulation. EMBO J. 2009;28(20):3103-16.

39. Mori Y, Takamori S. Molecular signatures underlying synaptic vesicle cargo retrieval. Front Cell Neurosci. 2017;11:422.

40. Lou XL. Sensing exocytosis and triggering endocytosis at synapses: synaptic vesicle exocytosis-endocytosis coupling. Front Cell Neurosci. 2018;12:66. doi: https://doi.org/10.3389/fncel.2018.00066.

41. Haucke V, De Camilli P. AP-2 recruitment to synaptotagmin stimulated by tyrosine-based endocytic motifs. Science. 1999;285(5431):1268-71.

42. Schivell AE, Mochida S, Kensel-Hammes P, Custer KL, Bajjalieh SM. SV2A and SV2C contain a unique synaptotagmin-binding site. Mol Cell Neurosci. 2005; 29(1):56-64

43. Groffen AJ, Martens S, Diez Arazola R, Cornelisse LN, Lozovaya N, de Jong $A P$, et al. Doc2b is a high-affinity $\mathrm{Ca} 2+$ sensor for spontaneous neurotransmitter release. Science. 2010;327(5973):1614-8.

44. Hui E, Bai J, Wang P, Sugimori M, Llinas RR, Chapman ER. Three distinct kinetic groupings of the synaptotagmin family: candidate sensors for rapid and delayed exocytosis. Proc Natl Acad Sci U S A. 2005;102(14):5210-4.

45. Geppert M, Archer BT 3rd, Sudhof TC. Synaptotagmin II. A novel differentially distributed form of synaptotagmin. J Biol Chem. 1991;266(21): $13548-52$.

46. Marqueze B, Boudier JA, Mizuta M, Inagaki N, Seino S, Seagar M. Cellular localization of synaptotagmin I, II, and III mRNAs in the central nervous system and pituitary and adrenal glands of the rat. J Neurosci. 1995;15(7 Pt 1):4906-17.

\section{Ready to submit your research? Choose BMC and benefit from:}

- fast, convenient online submission

- thorough peer review by experienced researchers in your field

- rapid publication on acceptance

- support for research data, including large and complex data types

- gold Open Access which fosters wider collaboration and increased citations

- maximum visibility for your research: over $100 \mathrm{M}$ website views per year

At BMC, research is always in progress.

Learn more biomedcentral.com/submissions 